\title{
Records of two citrus pest whiteflies in Japan with special reference to their mating sounds (Homoptera: Aleyrodidae)
}

\author{
Kenkichi Kanmiya* and Rikio Sonobe ${ }^{1}$ \\ Biological Laboratory, School of Medicine, Kurume University, Kurume, Fukuoka 830-0011, Japan \\ ${ }^{1}$ Midori 3-36-10, Utsunomiya, Tochigi 321-0165, Japan \\ (Received 3 April 2002; Accepted 22 May 2002)
}

\begin{abstract}
A serious citrus pest, the ash whitefly, Siphoninus phillyreae Haliday, was first recorded in Honshu and Kyushu, Japan. The favored host plant is pomegranate (Punica granatum L.) from early summer to autumn. The adults migrate to a hedge plant (Photinia glabra (Thumb.) Maxim.) or rarely to a citrus plant (Citrus natsudaidai Hayata) before pomegranates shed their leaves in winter. Another citrus pest, the woolly whitefly, Aleurothrixus floccosus Maskell, was found from Nansei Islands to north of Tokunoshima Is., Japan. The distribution of these two pests and diagnostic features were detailed. Substrate-borne vibratory sounds produced during mating were elucidated, including new findings of male and female communication by reciprocal sound signals. It is suggested that the species-specific bioacoustic signals preserve useful information for the whitefly biosystematics of economic importance.
\end{abstract}

Key words: Aleyrodidae, pest whiteflies, citrus, mating behavior, bioacoustic signals

\section{INTRODUCTION}

The current distribution of pest whitefly species is mostly the result of man's intervention (Byrne et al., 1990). In the woody plants, citrus is often infested with whiteflies due to man's introduction. Mound and Halsey (1978) reported 65 whitefly species on citrus. The five most serious pests on citrus are orange spiny whitefly (Aleurocanthus spiniferus (Quaintance)), citrus whitefly (Dialeurodes citri (Ashmead)), citrus blackfly (Aleurocanthus woglumi Ashby), woolly whitefly (Aleurothrixus floccosus (Maskell)), and ash whitefly (Siphoninus phillyreae (Haliday)) (Byrne et al., 1990). The distribution of the orange spiny whitefly and citrus whitefly as well as the other two noneconomic citrus pests, Bemisia giffardi (Kotinsky) and Aleurotuberculatus aucubae (Kuwana) in Japan was reported earlier (Miyatake, 1980).

The presence of substrate-borne vibratory sounds in the Aleyrodidae was first reported by Kanmiya (1996a) in the greenhouse whitefly, Trialeurodes vaporariorum (Westwood). Subsequently, Kanmiya (1996b) found acoustic signals in four other Japanese aleyrodid species of the genera Bemisia, Trialeurodes, and Pealius. In a review of whitefly mat- ing signals, 13 species of seven genera in the family were enumerated (Kanmiya, 1998a). We report here the infestation on pomegranate (Punica granatum L.), photinia (Photinia glabra (Thumb.) Maxim.) and citrus (Citrus natsudaidai Hayata) by the ash whitefly in Honshu and Kyushu, and of the common guava (Psidium guajava L.) by the woolly whitefly in the Nansei Islands, Japan. Specifically, we present evidence for male mating signals and illustrate some diagnostic features for the morphology and bionomics of these species for identification.

\section{MATERIALS AND METHODS}

Samples and acoustic recording. Host plants infested with whitefly nymphs were collected from the fields and kept alive to adult emergence at $\mathrm{Ku}-$ rume University. Virgin male and female adults more than $24 \mathrm{~h}$-olds were paired and released into a small cylindrical plastic case which contained a piece of live host leaflet. Acoustic recordings were conducted in an anechoic room at $25 \pm 1^{\circ} \mathrm{C}$. The signal recording and analyzing systems are reported elsewhere (Kanmiya, 1996a). Briefly, the mating behavior was monitored with a color video

\footnotetext{
* To whom correspondence should be addressed at: E-mail: kanmiya@med.kurume-u.ac.jp
} 
camera (CCDZ1, SONY, Tokyo, Japan) installed in the anechoic chamber, and the output was fed to a digital video master (NV-DV10000, Panasonic, Tokyo, Japan) together with output of the acoustic signals.

\section{RESULTS}

\section{Aleurothrixus floccosus (Maskell)}

Woolly whitefly (Japanese name=Mikan-watakonajirami)

Aleurodes floccosa Maskell, 1895: 432-433 (Jamaica).

Aleurothrixus floccosus (Maskell): Quaintance and Baker, 1914: 103.

Aleurothrixus floccosus: Kanmiya, 1998b: 6 (Ishigaki and Iriomote Is.); Martin et al., 2000: 420 (Okinawa).

Specimens examined. Host: common guava (Psidium guajava L.). Numerous nymphs on the host with sooty molds and leaf shedding (Dec. 26, 1997; July 14, 1998; June 23, 2000; Oct. 5, 2001, K. Kanmiya leg. in Barabido Tropical Botanical Garden, Ishigaki-shi, Ishigaki Is.). Numerous nymphs and adults on the host seedlings (July 18, 1998, K. Kanmiya leg. in the Research Institute of Tropical Agriculture, University of the Ryukyus, Funaura, Iriomote Is.). All stages on the host with heavy sooty molds (July 19, 1998, K. Kanmiya leg. in Yubujima Kanko Farm, Yoshihara, Iriomote Is.). Eggs and nymphs (June 23, 2000, K. Kanmiya leg. in residential district and farmhouses, Itona and Yoshihara, Ishigaki Is.). Eggs and nymphs (June 22, 2000, K. Kanmiya leg. in Yaeyama Branch of Okinawa Agricultural Experiment Station, Hirara, Miyako Is.). Eggs and nymphs (Dec. 20, 1998, K. Kanmiya leg. in a guava farm, Bane, Isen-cho, Tokunoshima Is.).

Diagnosis and bionomics. Puparium (Fig. 1A) with distinct suture-like folds sectioned between the submarginal and subdorsal areas, posterior fold complete between vasiform orifice and caudal puparial margin, puparial margin evenly deflected. Third and 4th nymphs and pupae covered with dense, wool-like white wax filaments (Fig. 1C), and the outline of nymphs often obscured in the final nymphal stage.

Eggs were oviposited on the underside of the fully expanded young yellowish green guava leaves as a circular patch with powdery white waxes. The heavily infested guava leaves were covered with sooty molds (Fig. 1B). These molds grew on honeydew excreted by whitefly nymphs and adults. Severe damage resulted in premature leaf shedding from some trees in guava farms and botanical gardens in Ishigaki and Iriomote Islands, Japan. Bionomics and phenology are detailed in Watson (1915), Paulson and Beardsley (1986), Miklasiewicz and Walker (1990), Rose and DeBach (1994), Salinas et al. (1996).

Distribution. Japan (Iriomote Is., Ishigaki Is., Miyako Is., Okinawa, Tokunoshima Is.), Palaearctic Region (Southern Europe, Mediterranean), Afrotropical Region, Oriental Region (India, Philippines), Nearctic Region (U.S.A.), Neotropical Region (Central and South America).

Host plants. The whitefly is known to have a wide host range in ornamental and horticultural plants. Mound and Halsey (1978) reported 25 host species from 18 families in the world. Paulson and Beardsley (1986) reported over 50 host species in 39 genera of 31 families in Hawaii. The whitefly is known to cause damage to Citrus spp. (orange grapefruit, and lemon), guava, and seagrape. Salinas et al. (1996) listed 14 host plants in seven families in the Philippines, including lemon, lime, mandarin, pummelo, and sweet orange, as well as guava and eggplant. In Japan, however, our survey in 1997-2001 did not find the whitefly on any Citrus spp. in the Nansei Islands, Japan. The host plant is limited to the common guava, not strawberry guava (P. littorale Raddi var. longipes Fosb.).

Mating behavior and sound signals. During mating, the male and female produced a large number of substrate-vibratory sounds (short burst and pulse sounds) until copulation (Fig. 2A-D). This series of sounds lasted for as long as $8 \mathrm{~min}$ through copulation, or even longer when mating failed (Table 1). Temporal features of the male sounds varied with the behavioral processes as shown in Fig. 2. Before recognizing the female, the male produced sounds of short bursts with irregular intervals (Fig. 2A and C), then, the sounds changed to a train of longer bursts when approaching and receiving sounds from a responding female (Fig. 2B). We named them calling and courtship sounds, respectively. The male and female made reciprocal communication (correspond sounds in Fig. 2C) throughout the main mating performance. Finally, the male produced quite a long sound of lower 

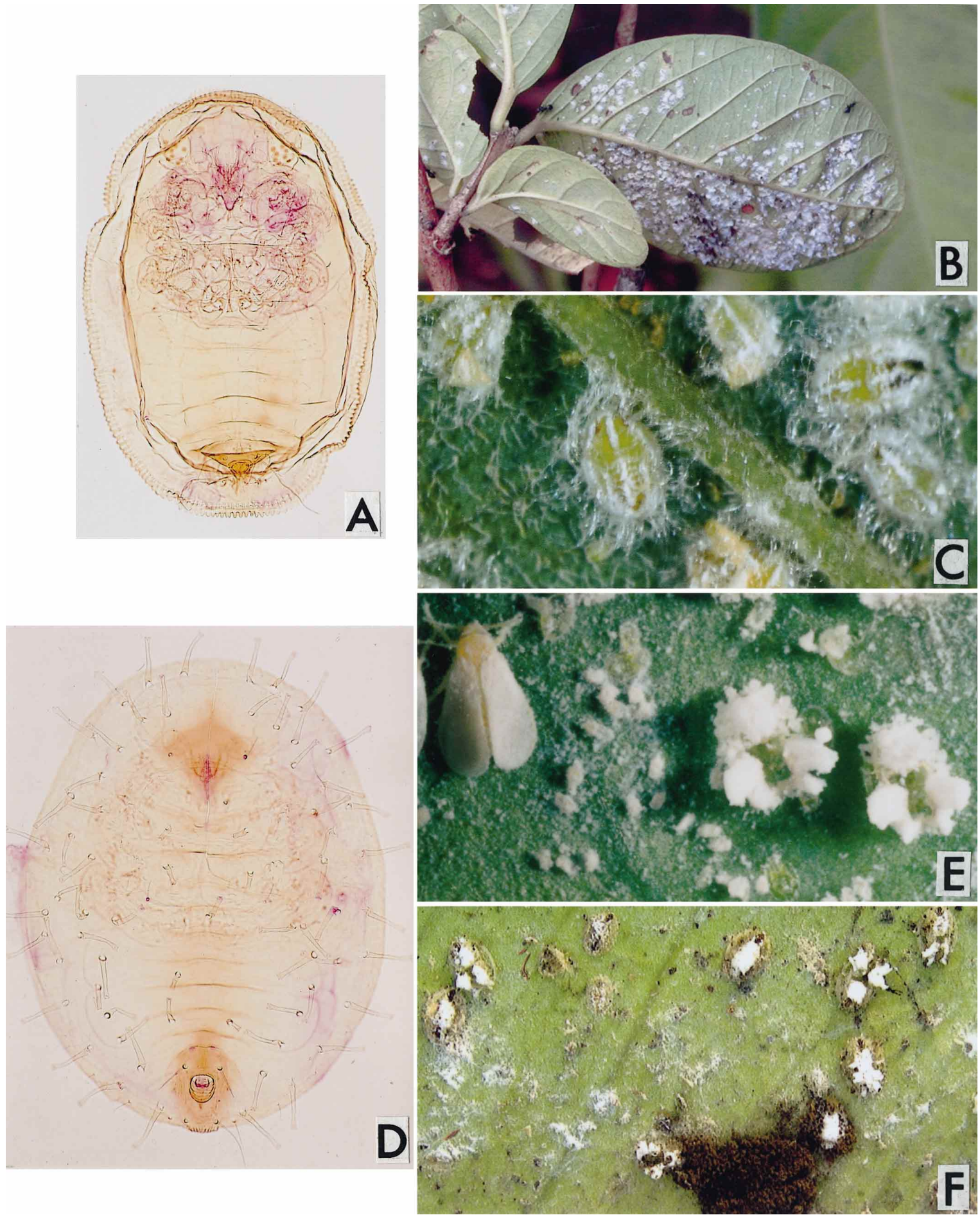

Fig. 1. Aleurothrixus floccosus (Maskell). A. Fourth instar nymph. B. infested guava leaf with sooty mold. C. Third instar nymph with wool-like wax filaments (all data as Oct. 5, 2001, Ishigaki Is.). Siphoninus phillyreae (Haliday). D. Fourth instar nymph (Nov. 10, 2000, Tokyo). E. Adult, nymph, and pupal cases on pomegranate (Sept. 8, 1999, Utsunomiya). F. Pupal cases on Watson pomelo, Citrus natsudaidai Hayata (June 18, 2001, Kurume). 
peak frequency with a mean duration of $16.55 \pm 3.77 \mathrm{~s}$ (range $12.62 \pm 20.2 \mathrm{~s}, N=4$ ) before mounting his courting female. This continuous sound is called pre-mating sound (Fig. 2D and K, Fig. 4E and F). The receptive virgin female started producing response sounds of short bursts when the male closely oriented to her, and finally the pair continued producing reciprocal sounds up to copulation. The female response rate gradually increased towards copulation as shown in Fig. 2B and $\mathrm{C}$ and added a series of pulse sounds in the final stage of mating behavior (Fig. 2I and J, Fig.

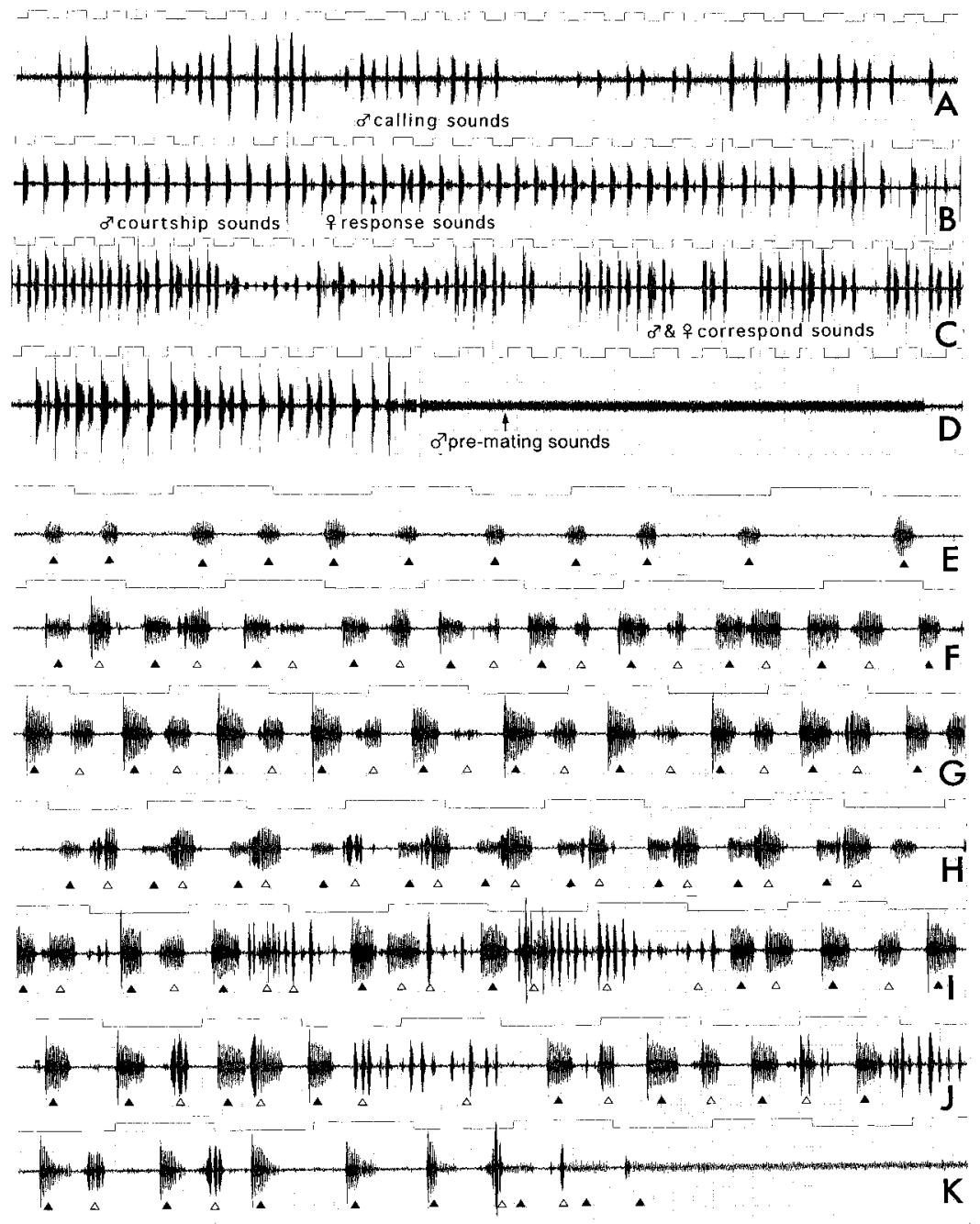

Fig. 2. Oscillograms of vibratory sounds in Aleurothrixus floccosus (Maskell) from Iriomote Is. A-D. A series of compressed oscillograms. E-K. Enlarged oscillograms showing the sounds by a male $(\boldsymbol{A})$ and a female $(\triangle)$. Upper square waves indicate a $1 \mathrm{~Hz}$ oscillation.

Table 1. Summary of male and female vibratory sounds within the complete mating process in Aleurothrixus floccosus (Maskell)

\begin{tabular}{lccccc}
\hline Location & $\begin{array}{c}\text { Total time } \\
(\mathrm{min})\end{array}$ & $\begin{array}{c}\text { Male sound } \\
\text { (number) }\end{array}$ & $\begin{array}{c}\text { Female sound } \\
\text { (number) }\end{array}$ & $\begin{array}{c}\text { Male sound period } \\
(\mathrm{s})\end{array}$ & $\begin{array}{c}\text { Female response rate } \\
(\% \text { to male sound) }\end{array}$ \\
\hline Ishigaki Is. & 7.53 & 206 & 105 & 2.19 & 51.0 \\
ditto & 8.24 & 265 & 134 & 1.86 & 50.6 \\
Iriomote Is. $^{\text {a }}$ & 11.18 & 602 & 265 & 1.15 & 44.0 \\
\hline
\end{tabular}

\footnotetext{
${ }^{\mathrm{a}}$ A case of mate failure.
} 

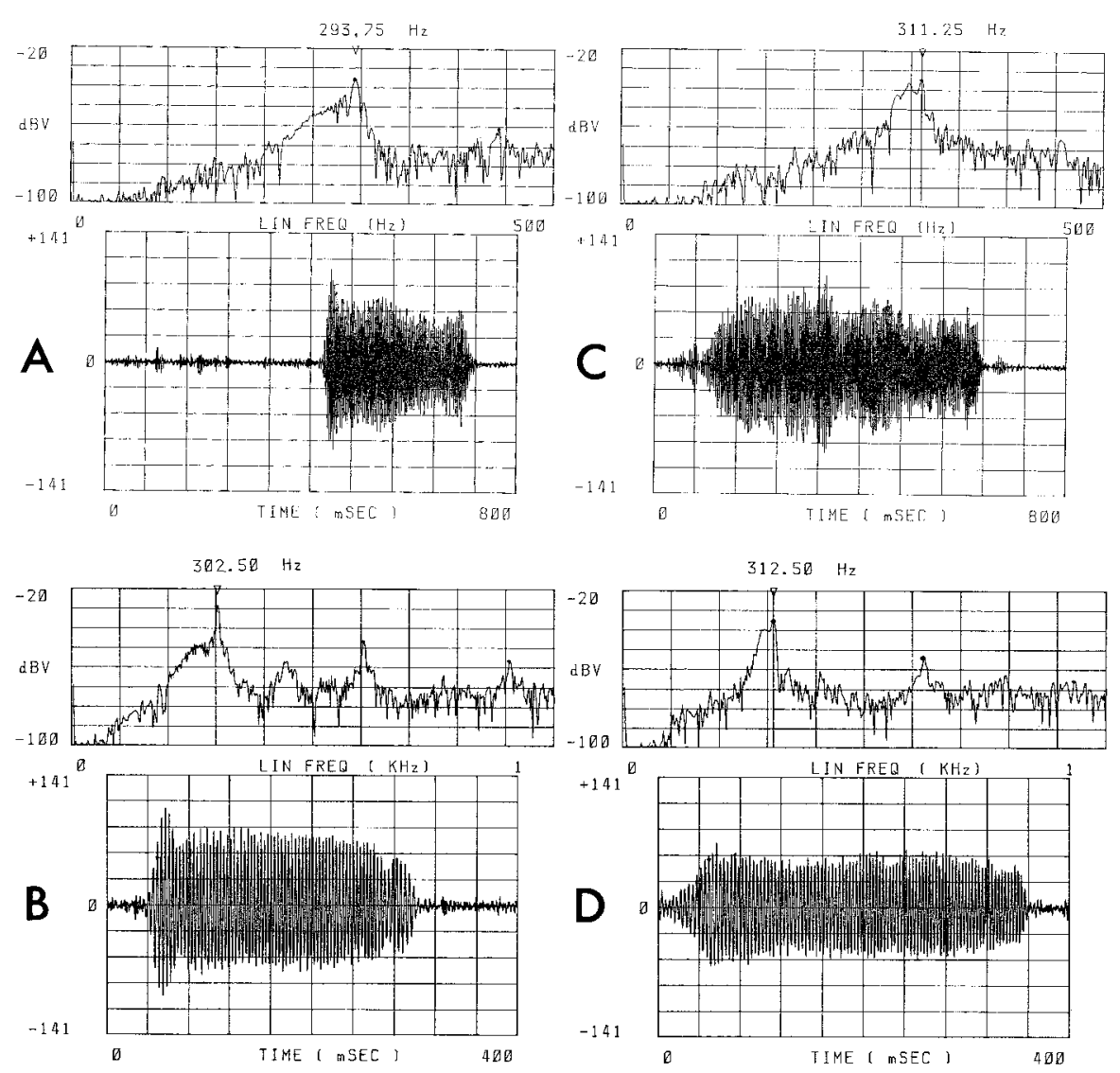

Fig. 3. Acoustic properties of vibratory sounds in Aleurothrixus floccosus (Maskell) from Iriomote Is. The graphs on the top of the series A-D are instantaneous power spectral density plots and the lower ones are their respective oscillograms. A and B. Male courtship sounds. C and D. Female response sounds. Sound durations (A, 295.6; B, 260.0; C, 542.7; D, 343.3 ms).

Table 2. Summary of acoustic properties of male calling and courtship sounds in Aleurothrixus floccosus (Maskell)

\begin{tabular}{|c|c|c|c|c|c|c|}
\hline \multirow[b]{2}{*}{ Location } & \multicolumn{2}{|c|}{ Burst duration } & \multicolumn{2}{|c|}{ Burst peak frequency } & \multicolumn{2}{|c|}{ Burst period } \\
\hline & $\begin{array}{c}\text { Calling } \\
\text { (ms) }\end{array}$ & $\begin{array}{l}\text { Courtship } \\
\quad(\mathrm{ms})\end{array}$ & $\begin{array}{c}\text { Calling } \\
(\mathrm{Hz})\end{array}$ & $\begin{array}{l}\text { Courtship } \\
(\mathrm{Hz})\end{array}$ & $\begin{array}{c}\text { Calling } \\
\text { (ms) }\end{array}$ & $\begin{array}{l}\text { Courtship } \\
\quad(\mathrm{ms})\end{array}$ \\
\hline Ishigaki Is. & $239.6 \pm 46.7$ & $224.7 \pm 48.5$ & $294.4 \pm 22.4$ & $292.6 \pm 16.2$ & $816.8 \pm 213.5$ & $911.5 \pm 144.6$ \\
\hline$N$ & 21 & 37 & 21 & 39 & 80 & 69 \\
\hline Iriomote Is. & $241.4 \pm 18.2$ & $247.9 \pm 30.8$ & $292.7 \pm 5.2$ & $294.6 \pm 6.7$ & $1,153.2 \pm 94.7$ & $996.1 \pm 76.2$ \\
\hline$N$ & 10 & 48 & 10 & 14 & 20 & 75 \\
\hline
\end{tabular}

Table 3. Summary of acoustic properties of female response sounds in Aleurothrixus floccosus (Maskell)

\begin{tabular}{cccc}
\hline Location & $\begin{array}{c}\text { Burst duration } \\
(\mathrm{ms})\end{array}$ & $\begin{array}{c}\text { Burst peak frequency } \\
(\mathrm{ms})\end{array}$ & $\begin{array}{c}\text { Peak frequency range } \\
(\mathrm{Hz})\end{array}$ \\
\hline Ishigaki Is. & $307.2 \pm 38.5$ & $308.1 \pm 9.0$ & $244.0 \pm 13.1-325.7 \pm 10.1$ \\
$N$ & 25 & $300.6 \pm 6.0$ & 25 \\
Iriomote Is. & $283.2 \pm 61.1$ & 10 & $228.1 \pm 26.2-314.2 \pm 5.0$ \\
$N$ & 29 & & 8 \\
\hline
\end{tabular}



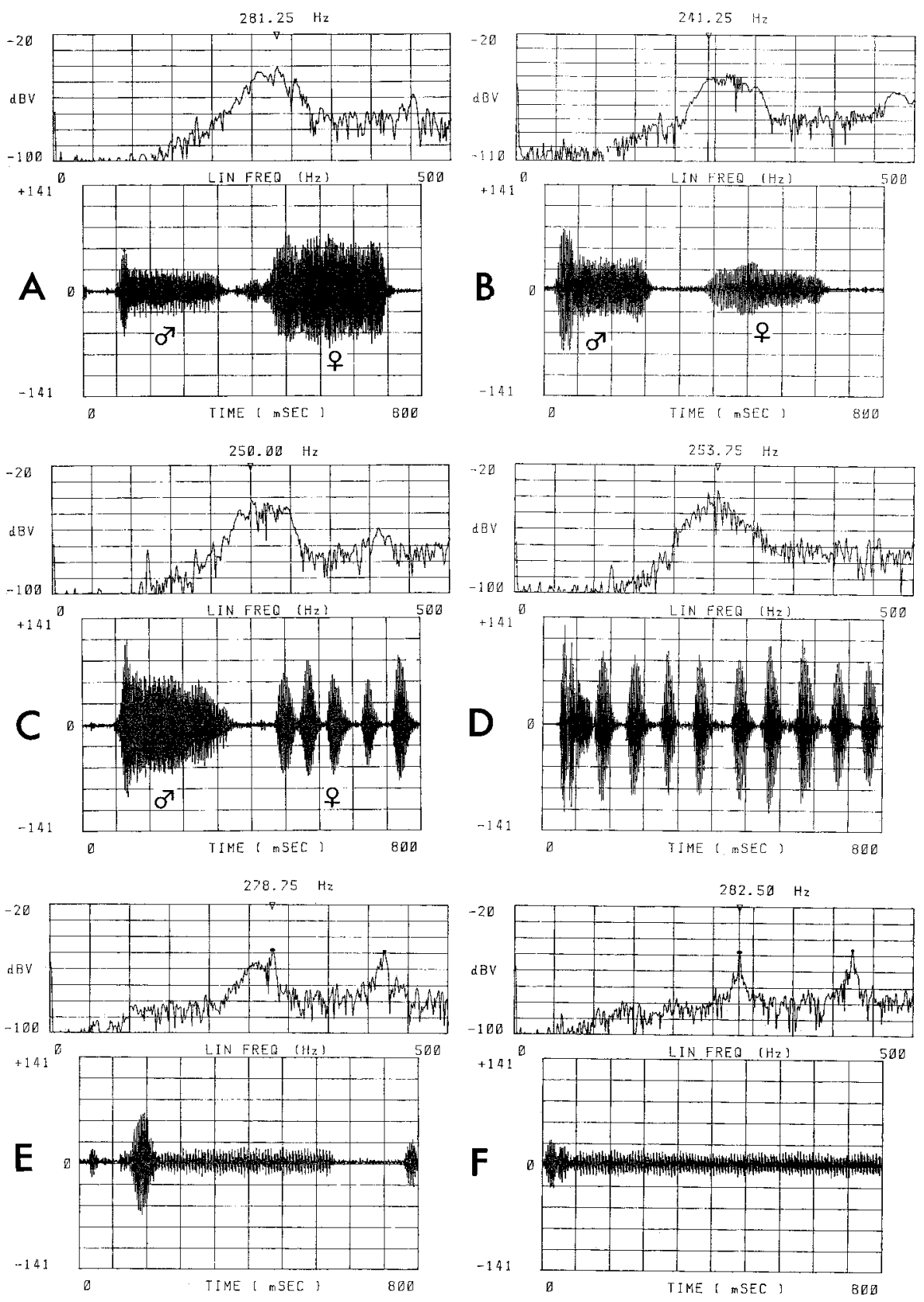

Fig. 4. Acoustic properties of vibratory sounds in Aleurothrixus floccosus (Maskell) from Iriomote Is. A-C. Male courtship sounds and female response sounds. D. Female response pulses. E. Start of male pre-mating sounds. F. Next male pre-mating sounds.

4C and D). Intervals of the response sounds from the female to the male varied with the courtship condition (Fig. 4A and B), partially overlapped the male courtship sounds (Fig. 2H). The female's total mean response rate reached $50 \%$ for all the male calling and courtship sounds in the cases of mating success (Table 1).

Acoustic properties of mating sounds. Enlarged oscillograms showed that the male and fe- male sounds were produced by vertical oscillation of their abdominal segments without wing movement (Fig. 3A-D). The male calling and courtship sounds were composed of a train of short bursts with a mean peak frequency of a little less than $300 \mathrm{~Hz}$ for both males of Ishigaki and Iriomote Is. (Table 2), without spectral differences between the sound types. Well-recognized characteristics are a peak frequency with a narrow range of variation so 
as to make an acute angle in the power spectral density plot (Fig. 3A and B). The mean duration of the male burst in the calling and courtship sounds (Table 2) was usually shorter than that of the female response sounds (Table 3). The male burst sounds were also characterized by an abrupt start in amplitude as shown in the power spectral density plot. The female sounds were also composed of a train of short burst, but well characterized by higher peak frequencies (Table 3) with a wide peak fluctuation in frequency (Fig. 3C and D). This frequency property may be produced by a smooth start and partial modulation at the end of the burst.

\section{Siphoninus phillyreae (Haliday)}

Ash whitefly (Japanese name=Zakuro-sirotogekonajirami)

Aleyrodes phillyreae Haliday, 1835: 119-120 (Ireland).

Siphoninus phillyreae (Haliday): Silvestri, 1915: 247.

Aleyrodidae sp.: Sonobe, 2000: 43 (record from Tochigi Pref., with figures of puparium)

Specimens examined. Host: pomegranate, Punica granatum L. Nymphs and pupae (unidentified date, 1996, Sakura, Utsunomiya, Tochigi Pref., R. Sonobe leg.). Nymphs and pupae (Sept. 8, 1997; May 18, 1998; April 9, 2000; April 16, 2000, Midori, Utsunomiya-shi, Tochigi Pref., R. Sonobe leg.). Pupae (Oct. 10, 1998, Matsugamine, Utsunomiya-shi, Tochigi Pref., R. Sonobe leg.). Pupae (Aug. 12, 2000, Nishikawada, Utsunomiya-shi, Tochigi Pref., R. Sonobe leg.). Pupae (Oct. 6, 1998, Ishibashi-cho, Shimotsuga-gun, Tochigi Pref., R. Sonobe leg.). Nymphs and adults (Nov. 12, 2000, Miyamoto-cho, Kiryu-shi, Gunma Pref., R. Sonobe leg.). All stages (Oct. 12, 2000; Nov. 10, 2000, Miyamoto-koen, Chiyoda-ku, Tokyo, K. Kanmiya leg.). All stages (Oct. 19, 2000; Oct. 22, 2000; Nov. 13, 2000, Shikanoshima, Higashi-ku, Fukuoka-shi, Fukuoka Pref., K. Kanmiya leg.). All stages (Sept. 26, 2000, Takada-machi, Saga Pref., K. Kanmiya leg.). Host: Japanese Photinie, Photinia glabra (Thumb.) Maxim. Nymphs (April 20, 1998; May 18, 1998; April 9, 2000; April 16, 2000, Midori, Utsunomiya-shi, Tochigi Pref., R. Sonobe leg.). Eggs (Nov. 12, 2000, Midori, Utsunomiyashi, Tochigi Pref., R. Sonobe leg.). Host: Watson pomelo, Citrus natsudaidai Hayata. Pupal cases (June 18, 2001, in Vegetable and Ornamental Crop
Research Station, Kurume Branch, Kurume, Fukuoka Pref., K. Kanmiya leg.).

Diagnosis and bionomics. Puparium characterized by operculum restricted to the basal part of vasiform orifice and exposed lingula head; vasiform orifice floor with many small areolae; puparial margin predominantly smooth except for the caudal margin (Fig. 1D). In the thoracic dorsum of mature nymph and pupal stages was largely covered with fluffy tufts of white wax (Fig. 1E) and the dorsal surface and lateral margin prominently fringed with many elongate siphon-like wax tubes (Fig. 1D). The apices of these tubes were simple and truncate, not bifurcate, usually tipped with a small amount of glassy wax.

The ash whitefly has been known to infest a variety of crops and ornamental trees, especially citrus, apples and peas. In Japan, damaged trees have been limited to pomegranate. A rare case of infestation on citrus leaves is shown in Fig. 1F. Heavy infestations of whiteflies on pomegranate leaves can produce large amounts of honeydew and growth of sooty molds.

Distribution. Japan (Honshu, Kyushu). The whitefly is predominantly distributed in Palaearctic temperates to Mediterranean climates, extending to northern Afrotropical Regions, elsewhere in the Oriental (India, Pakistan), Pacific (Hawaii, New Zealand), Australia (N.S. Wales), South America (Mexico), and USA (California) (Mound and Halsey, 1978; Martin et al., 2000).

Host plants. This whitefly is highly polyphagous on woody plants, apple, pear and pomegranate as well as various ornamental plants. These preferred hosts are deciduous plants from spring to autumn. In autumn, adults migrate to winter hosts, usually citrus and other evergreen perennials, olive and photinia. In Japan, various stages of this species have been observed exclusively on pomegranate from early summer to autumn and in the egg stage on Japanese Photinie (Photinia glavra (Thumb.) Maxim. (Sonobe, 2000) in winter. The egg density in winter was very low, but became a source of infestations early in the next season.

Mating behavior and sound signals. Only the male produces mating sounds by oscillating its abdomen. The vibratory sounds for the female consist of well-separated chirps. The male produces such chirps sporadically while walking around on the host leaves. The chirps were irregularly inter- 

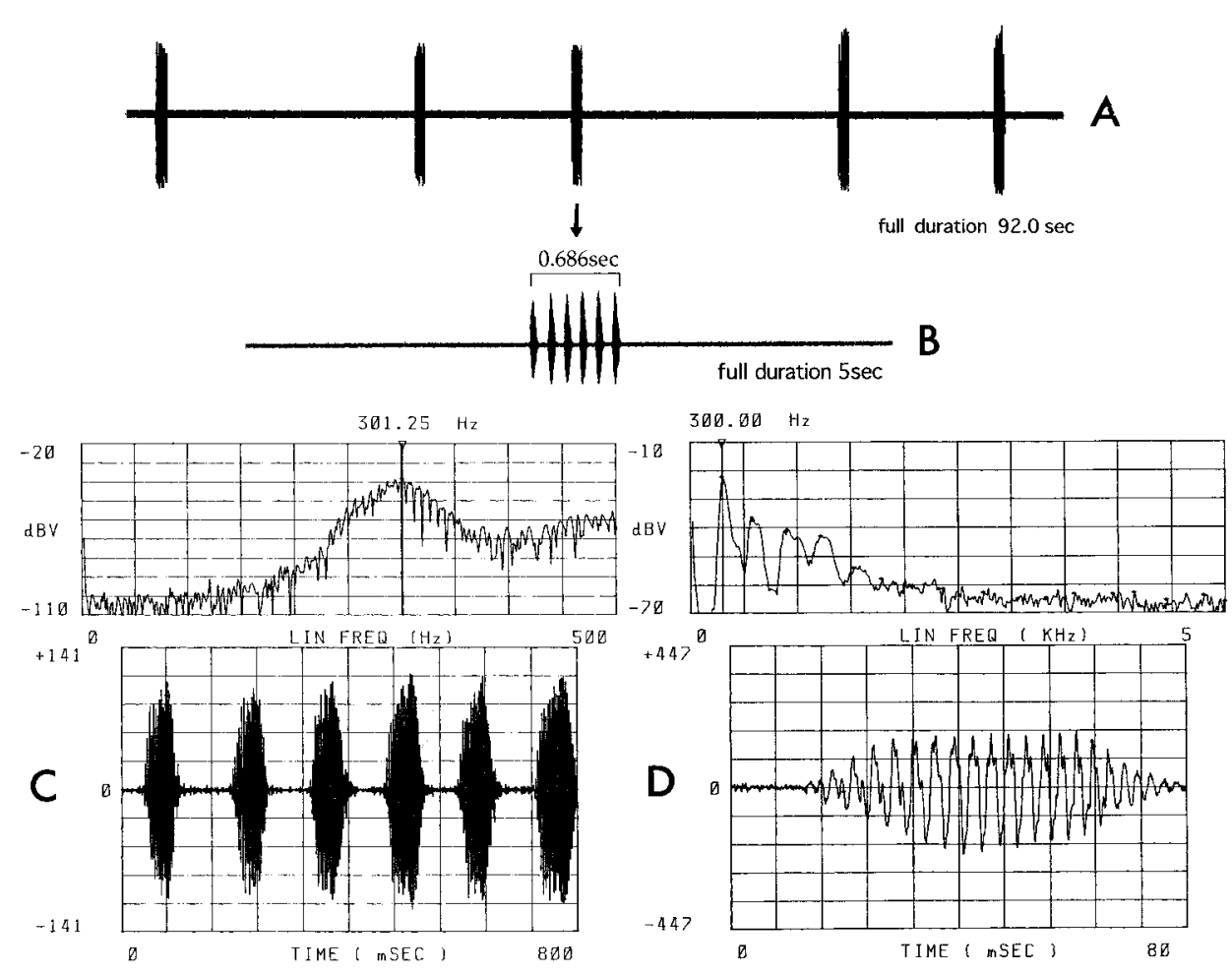

Fig. 5. Acoustic properties of vibratory sounds in Siphoninus phillyreae (Haliday). A. A long series of male chirp sounds. B. Enlarged oscillogram of a chirp. C. Oscillogram of a chirp and its instantaneous power spectral density plots. D. Mean power density plots of 16 pulses and an enlarged oscillogram.

spersed with intervals of more than $10 \mathrm{~s}$ (Fig. 5A). We did not find any continuous mating sounds in the male immediately before copulation as was observed in the woolly whitefly. The duration of a chirp was $759.69 \pm 43.35 \mathrm{~ms}(N=20)$, based on 5 males in Tochigi Pref. A chirp was composed of almost 6 syllables $(6.2 \pm 0.4, N=23)$ (Fig. 5B). As shown in the oscillogram (Fig. 5C), the syllables in a chirp were regularly placed with a $59.9 \pm 5.1 \mathrm{~ms}$ duration $(N=23)$ and $70.4 \pm 9.3 \mathrm{~ms}$ interval $(N=$ 16). The enlarged oscillogram of a single syllable in Fig. 5D shows 16 complex pulses with a period of $3.2 \pm 0.5 \mathrm{~ms}$. This pulse period indicates the fundamental frequency of the chirp, about $300 \mathrm{~Hz}$ in the upper trace of Fig. 5D. The oscillogram of a syllable is similar to free flight sounds, but the sound waves of the free flight have a fundamental frequency of $190.2 \pm 5.9 \mathrm{~Hz}$, significantly different from the syllable shown in the power spectrum density plot. The complex sound pulses produce up to the 4th harmonic in most cases. The mean fundamental frequency and the $2 \mathrm{nd}, 3 \mathrm{rd}$, and 4th harmonics were $296.45 \pm 6.48 \mathrm{~Hz}, 539.50 \pm 14.35 \mathrm{~Hz}$, $857.30 \pm 7.32 \mathrm{~Hz}$, and $1181.25 \pm 16.25 \mathrm{~Hz}$, respec- tively.

\section{DISCUSSION}

The woolly whitefly seems to have predominantly been distributed in Central and South America (Mound and Halsey, 1978). However, its progressive dissemination to other regions has been noticeable, namely, extending to North America in the 1960's, Southern Europe, Mediterranean and Africa in the 1970's, Pacific Islands (Guam and Hawaii) in the 1980's, and Southern and Eastern Asia (India, Philippines) in the 1990's. The whitefly has a wide host range (Mound and Halsey, 1978), and is well known for its detriment to Citrus spp., orange, and grapefruit trees. Our surveys in 19972001 in the Nansei Islands (Iriomote Is., Ishigaki Is., Miyako Is., Okinawa, Tokunoshima Is.) did not reveal any citrus infested with this species. In the botanical gardens and guava farms in these Islands, we observed serious damages to fruit guava. Successive generations of infestation resulted in sooty molds and partial defoliation. The infested guavas consisted of several edible strains of $P$. guajava, 
but rarely of the foliage species, strawberry guava. Our survey in Amami-oshima Is. in 1998 and 1999 did not reveal any guava infested by this species. The species was not recorded in Taiwan until 2000 (personal communication, C. C. Ko of Taiwan Univ., Taipei, Taiwan).

Report of ash whitefly in this paper is the first record in Japan. Sonobe (2000) reported an unidentified whitefly with two images of pupal cases and notes on its bionomics as follows: all stages of the whitefly were observed on pomegranate in summer and the species overwintered as eggs on a Japanese Photinie. His notes and figures coincide with the present species. There were many generations a year, and all stages were observed on pomegranate leaves from May to November in Kyushu. The last nymphal stage was parasitized by hymenopterous parasites, Encarsia spp., in Honshu and Kyushu.

The male mating signals of the present two whiteflies are the first record. The acoustic properties of the two species are easily distinguishable from those of other known aleyrodid species (Kanmiya, 1996a, b). The presence of response sounds in the female for the male is probably an exception for the family. As pointed out in an earlier review (Kanmiya, 1998a), the acoustic sounds produced by the adult male in their prolonged courtship behavior can be used as a reference for species identification, because their species-specific sounds appear to play a significant role in species-recognition during the reproductive processes.

\section{ACKNOWLEDGEMENTS}

We are deeply indebted to Chang-chi Chu of USDA-ARS Western Cotton Research Laboratory, Phoenix, AZ, USA for his editing of the manuscript, and Chiun Cheng Ko of the Laboratory of Insect Systematics, National Taiwan University, Taipei, Taiwan for his providing invaluable assistance in taxonomics and literature. We also thank A. Tanaka of Tokunoshima Branch of Kagoshima Agricultural Experiment Station, M. Nakasone of Yaeyama Branch of Okinawa Agricultural Experiment Station, M. Kinjyo of Research Institute of Tropical Agriculture, University of the Ryukyus, and T. Kashio of Vegetable and Ornamental Crop Research Station, Kurume Branch, for arranging our field studies. This study was supported by a grant-in-aid for scientific research from the Ministry of Education, Science, Sports and Culture of Japan (No. 09660054), and research funds from Sumitomo Chemical Co. Ltd. and Ishibashi Zaidan Foundation of Kurume University. Valuable comments of anonymous reviewers improved the manuscript.

\section{REFERENCES}

Byrne, D. N., T. S. Bellows, Jr. and M. P. Parella (1990) Whiteflies in agricultural systems. In Whiteflies: Their Bionomics, Pest Status and Management (D. Gerling ed.). Intercept, Andover, Hants, pp. 227-262.

Haliday, A. H. (1835) Aleyrodes phillyreae. Entomol. Mag. 2: $119-120$

Kanmiya, K. (1996a) Discovery of male acoustic signals in the Greenhouse whitefly, Trialeurodes vaporariorum (Westwood) (Homoptera: Aleyrodidae). Appl. Entomol. Zool. 31(2): $255-262$.

Kanmiya, K. (1996b) Discovery of male acoustic signals in whitefly genera, Bemisia, Trialeurodes and Pealius (Homoptera: Aleyrodidae). Proc. XX Intern. Congr. Entomol. 1996: 475.

Kanmiya, K. (1998a) Mating behavior and vibratory signals on whiteflies. Plant Protection 52: 17-22 (in Japanese).

Kanmiya, K. (1998b) Report on a new exotic pest whitefly, Aleurothrixus floccosus (Maskell) from Japan. Delfax 42: 6 (in Japanese).

Martin, J. H., D. Mifsud and C. Rapisarda (2000) The whiteflies (Hemiptera: Aleyrodidae) of Europe and the Mediterranean Basin. Bull. Entomol. Res. 90: 407-448.

Maskell, W. M. (1895) Contributions towards a monograph of Aleyrodidae, a family of Hemiptera-Homoptera. Trans. Proc. N.Z. Inst. 28: 411-449.

Miklasiewicz, T. J. and G. P. Walker (1990) Population dynamics and biological control of the Woolly whitefly (Homoptera: Aleyrodidae) on Citrus. Environ. Entomol. 19: 1485-1490.

Miyatake, Y. (1980) A list of the whiteflies of Japan with their host plant and distribution data (Homoptera: Aleyrodidae). Rostria 32: 291-330 (in Japanese).

Mound, L. A. and S. H. Halsey (1978) Whitefly of the World. A Systematic Catalogue of the Aleyrodidae (Homoptera) with Host Plant and Natural Enemy Data. British Museum (Natural History) and John Wiley \& Sons, London. 340 pp.

Paulson, G. S. and J. W. Beardsley (1986) Development, oviposition and longevity of Aleurothrixus floccosus (Homoptera: Aleyrodidae). Proc. Hawaii Entomol. Soc. 25: $103-124$

Quaintance, A. L. and A. C. Baker (1914) Classification of the Aleyrodidae. Part II. U.S.D.A. Bur. Entom. Tech. Ser. 27: 95-109.

Rose, M. and P. DeBach (1994) The woolly whitefly of Citrus, Aleurothrixus floccosus (Homoptera: Aleyrodidae). Vedalia 1: 29-60.

Salinas, M. D., A. C. Sumalde, V. J. Calilung and N. B. Bajet (1996) Life history, seasonal abundance, host range and geographical distribution of the Woolly whitefly, Aleurothrixus floccosus (Maskell) (Homoptera: Aleyrodidae). Philipp. Entomol. 10: 67-89.

Silvestri, F. (1915) Contributo alla conoscenza degli insetti dell' olivo dell' ritrea e dell' Africa meridionale. Fam. Aleyrodiae. Boll. Lab. Zool. gen. agr. R. Scuola Agric. Portici 9: 245-249.

Sonobe, R. (2000) Records of whiteflies from Tochigi Prefecture (part 2). Insect 51: 42-43 (in Japanese).

Watson, J. R. (1915) The woolly whitefly. Fl. Exp. Sta. Bull. 136: 82-102. 